\title{
InSAR Observation for the Surface Displacements at Mt. Etna between 2003 and 2007
}

\author{
Syeda Sabikun Nahar, Arif Mahmud \\ BGMEA University of Fashion and Technology, Dhaka, Bangladesh \\ Email: alee.nahar@buft.edu.bd
}

Received 12 January 2015; accepted 7 February 2015; published 11 February 2015

Copyright (C) 2015 by authors and Scientific Research Publishing Inc.

This work is licensed under the Creative Commons Attribution International License (CC BY). http://creativecommons.org/licenses/by/4.0/

(c) (i) Open Access

\section{Abstract}

This research is mainly devoted to InSAR observations using Poly-Interferogram Rate and Timeseries Estimator ( $\pi$-rate) software to investigate continuous surface displacement at Mt. Etna (Sicily), Italy between 2003 and 2007. Using ascending and descending SAR images produced by European Space Agency's ENVISAT, we generate a set of interferograms which are used to determine the deformation history of Etna from 2003 to 2007. Using ( $\pi$-rate), we can generate the InSAR time-series and ratemap while minimizing errors induced by the satellites orbit and atmospheric phase delays. During the period of 2003-2007, three separate eruptions were observed. In order to explain the deformation, we solve three displacement rate for 2003-2005, 2006 and 2007. As expected, the result suggests that displacement rates are not constant with respect to time. During 2006 the volcano appeared to switch from a period of deflation to a period of inflation. These results highlight the importance of InSAR for generating deformation time-series around Mt. Etna, and with the application of numerical models these results can be used to estimate the amount of magma moving in the subsurface.

\section{Keywords}

InSAR, Interferogram, Ratemap, Eruptions, Magma and $\pi$-Rate

\section{Introduction}

Volcanoes are the surface manifestation of dynamic and complexly coupled physical and chemical processes occurring in the interior of the Earth [1]. Volcanoes typically occur at plate boundaries where tectonic plates separate or where tectonic plates come together with one plate subducting below the other into the mantle [2]. 
Conversely, another type of volcanism, known as intraplate volcanism, occurs far from plate boundaries and its origin is rather controversial [1].

To understand the dynamics of volcano, it is necessary to study the interplay between tectonics, deformation processes and magma transport through the lithosphere. Deformation induced fault-fracture networks are considered efficient pathways through which magma is transported, stored and eventually erupted at the Earth surface [1] (Figure 1).

The eruptive behavior depends upon when (frequency), where (which portion) and how (eruptive style and rate) a volcano erupts its magma [3]. Before an eruption, magma rises up towards the surface and can stagnate at different levels in the litho-sphere, giving rise to magma bodies of different shapes and sizes [4]. Nearly all volcanic eruptions are supplied with magma through dykes and inclined sheets whose initiation and eventual propagation to the surface result in an eruption. Alternatively, magma may arrest at some depth in the volcano, depending on the stress state in the volcano [5]. The majority of eruptive fissures have a radial configuration at the surface of active volcanic edifices, while tangential or oblique fissures are rare [1]. At many eroded volcanic edifices, dykes and dyke-fed eruptive fissures commonly have more complex patterns because of regional stresses, magmatic reservoirs, anisotropy or variations in topography [5].

\subsection{Tectonic Setting}

Mt. Etna is located at the subduction zone of the Nubian and the Eurasian tectonic plates [1]. It lies between $37.73 \mathrm{~N}$ and 15.00 E [6], and it is the largest active volcano in Europe and dominates the landscape of NE Sicily, Italy. It has the longest period of recorded eruptions in the world, a maximum elevation of about $3350 \mathrm{~m}$ and an elliptical base $38 \times 47 \mathrm{~km}$. It covers an area of about $1250 \mathrm{~km}^{2}$ with a basal circumference of $140 \mathrm{~km}[1]$ (Figure 2).

Mt. Etna lies on the Sicilian continental crust and is located on the external boundary of the Apennine-Maghrebian chain, which is close to the Gela-Catania Plio-Quaternary foredeep. The structural features of Mt. Etna appear rather complex. On the volcano surface different fault and fissure systems can be recognized. The most outstanding tectonic features at Mt. Etna are clearly recognizable on the east and south-east flanks of the volcano, where the clearest morphological evidence of active faulting exists. Here, seismogenic faults can be related to the NNW-SSE Malta Escarpment that is the main lithospheric structure in the eastern Sicily. Other seismogenetic faults, though not recognizable on the surface, can be linked to the NE-SW, ENE-WSW fault systems that control the tectonic evolution of the northern margin of the Hyblean Plateau. The eastern flank of Mt. Etna is characterized by frequent shallow seismic activity (depth $<7 \mathrm{~km}$ ) and by a seismic creep along some faults. Conversely, the western flank of Mt. Etna, normally characterized by a deeper seismicity (depth $>5 \mathrm{~km}$ ), is considered the most stable sector of the volcano. In the western sector, there is only slight morphological evidence of faulting, such as some short segments of faults observable on the south-western flank (e.g. Ragalna fault). However, it must

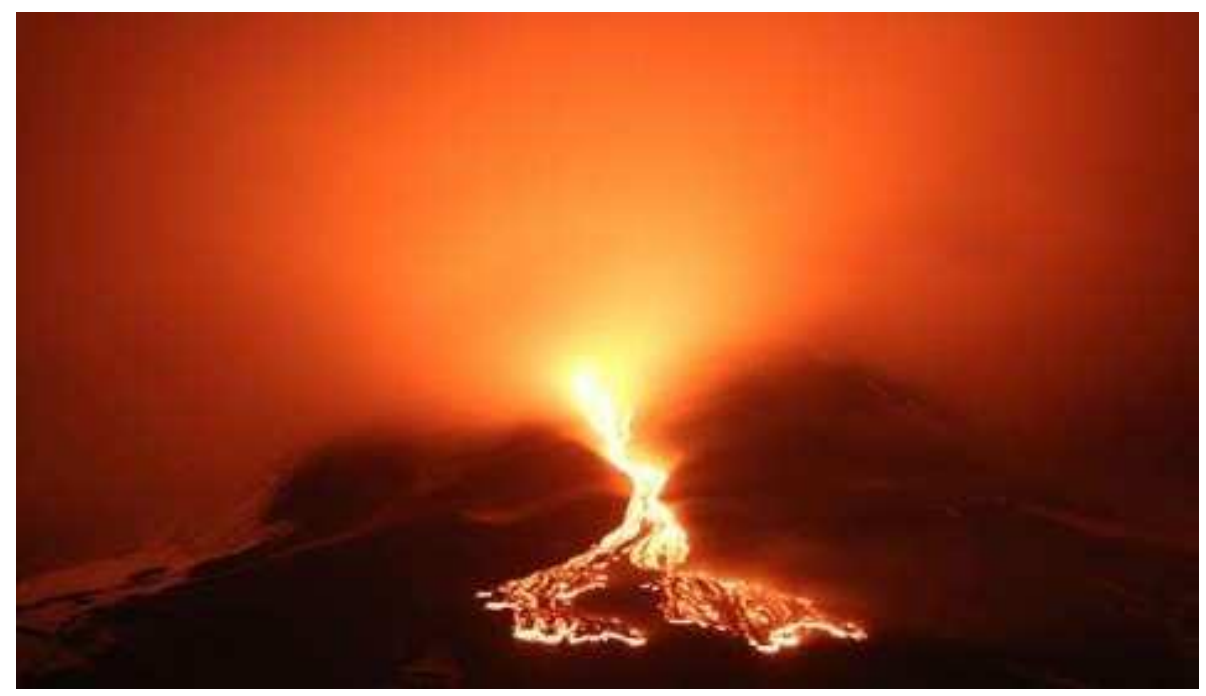

Figure 1. Active volcano at Mt. Etna. (abcnews.go.com). 


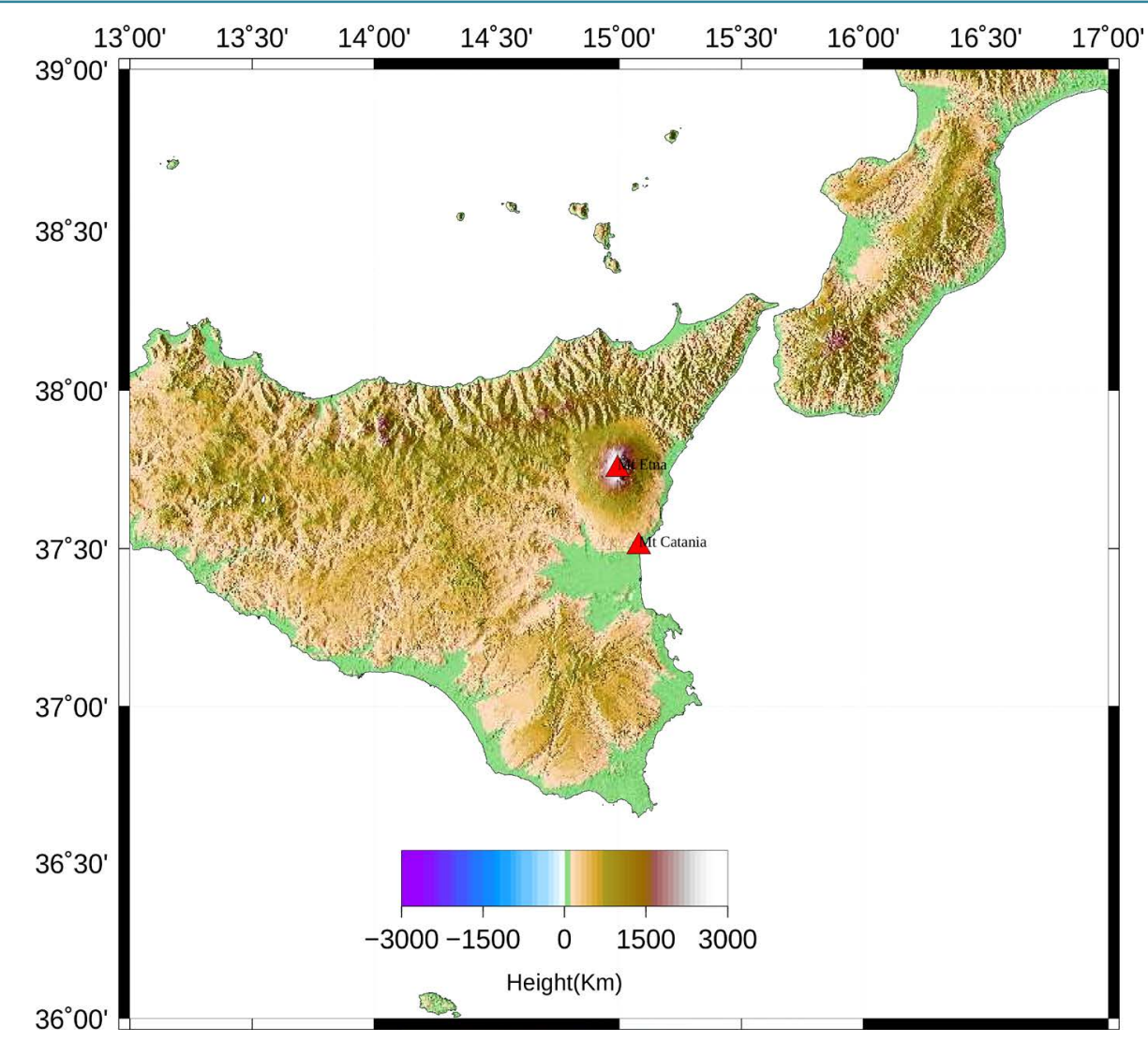

Figure 2. The image of digital elevation model of Mt. Etna at Sicily, Italy.

be noted that the faults with morphological evidence may represent only a part of the tectonic structures present in the Etnean area and that hidden fault segments can be covered by the huge pile of volcanic products [1].

Etna experiences the wide variety of eruption styles. Almost continuous eruptive activity from its summit craters and fairly frequent lava flow eruptions from fissures opened on its flanks [7]. It consists of a sequence of nested stratovolcanoes, characterized by summit calderas. It was the most important one being the Ellittico caldera, which formed about 14,000 - 15,000 years ago [8]. Historically, Mt. Etna has shown mostly effusive activity, but several pyroclastic deposits related to Plinian eruptions have been identified in the Holocene sequence [9]. Four craters are currently active on the volcano summit: Voragine, Bocca Nuova, S-E Crater and N-E Crater [10]. Ash emissions only occur during flank eruptions of Mt. Etna [11]. N-S compression generally dominates the regional deformation in the area of Etna as indicated by structural and seismic data [12].

\subsection{Eruption History at Mt. Etna}

Eruptions at Mt. Etna have been recorded since the 15th century BC. At that time, eruptions were known as Phreato-magmatic eruptions. To date, over 200 eruptions have been recorded, though all of them are not large. The most powerful eruption recorded in 1669 destroyed part of the summit and caused lava flows from a fissure on the volcanic flank which covered more than $16 \mathrm{~km}^{2}$. At that time, it reached to the seas and towns of Catania. In 1775, another eruption produced large lahars (mud flow of volcanic fragments). An extremely violent eruption in 1852 covered almost $8 \mathrm{~km}^{2}$ and produced more than $5.5 \mathrm{~km}^{3}$ of lava. The longest eruption lasted for 13 years and started in 1979. The most recent eruption began in March 2007 and eruptions are still going on.

\section{Methodology}

Since the launch of ERS-1 in 1992, InSAR (Interferometric Synthetic Aperture Radar) has become a powerful tool for mapping surface deformation [13]. InSAR utilizes radar waves, which propagate along the satellite's line of sight (LOS), hit targets on the ground within a swath of finite width, are reflected back from the ground 
surface and received by the antenna and encoded as complex numbers, $z=A \mathrm{e}^{i \varnothing}$, where, $A$ is the amplitude component and $\varnothing$ is the phase component. The amplitude component represents the reflective properties of the ground surface. The phase component is a measure of path length between the ground and satellite. It is an active system with day and night operational capabilities. A measurement of the travel path is a function of satellite position and time of acquisition. The variations allow generation of Digital Elevation Models (DEM) and measurement of centimetric surface deformations of the terrain.

Consider, two radar images of a ground target are taken at different times, taking the difference between the phase in the master (first acquisition) and the slave (second acquisition) provides information on any changes the path length between the two times [14]. To get the observed fringe pattern in an interferogram $\Delta \varnothing_{\text {int }}$ a number of phenomena are combined [13]:

$$
\Delta \varnothing_{\text {int }}=\Delta \varnothing_{\text {def }}+\Delta \varnothing_{\text {coh }}+\Delta \varnothing_{\text {orb }}+\Delta \varnothing_{\text {topo }}+\Delta \varnothing_{\text {atm }}+\Delta \varnothing_{\text {other }}
$$

where, $\Delta \varnothing_{\text {def }}$ is the deformation signal of interest, $\Delta \varnothing_{\text {coh }}$ is the decorrelation of the signal, $\Delta \varnothing_{\text {orb }}$ is the signal associated with the orbital geometry, $\Delta \varnothing_{\text {topo }}$ is the topographic phase related to viewing the surface from different locations, $\Delta \varnothing_{\text {atm }}$ is the atmospheric noise, $\Delta \varnothing_{\text {other }}$ is any other source of noise. The symbol $\Delta$ refers to the differencing of each signal component at the master and slave epochs.

Assuming that $\Delta \varnothing_{\text {orb }}, \Delta \varnothing_{\text {topo }}$ and $\Delta \varnothing_{\text {atm }}$ are successfully removed, the remaining signal is a reset of any change in the surface position. If the surface has moved then a phase change will be observed between two acquisitions, the measured signal will be related to [15]:

$$
\Delta \varnothing_{\text {def }}=\frac{4 \pi \Delta r}{\lambda}=\left(\frac{4 \pi}{\lambda}\right) \boldsymbol{l} \cdot \boldsymbol{u}
$$

where, $\boldsymbol{u}$ is the ground displacement vector, $\boldsymbol{l}$ is a unit vector from the ground target to satellite.

To avoid noise in interferogram, unwrapped data were taken to use as input data to the ( $\pi$-rate) software. The ( $\pi$-rate) software is based on Matlab codes written by Biggs et al., 2007, Elliott 2008, wang et al., 2010 [16]. The input is geo-coded, unwrapped set of interferograms. ( $\pi$-rate) effectively estimates a velocity map of steady-state deformation on a pixel by pixel basis, estimates deformation time-series and estimates uncertainty, orbital error and atmospheric delays are also removed from the interferogram during the ratemap inversion.

\section{Result}

Using ascending data on track-129 and descending data on track-222, we have computed a set of 39 unwrapped, geocoded interferograms and on descending track-222, a set of 26 unwrapped, geocoded interferograms. In general, interferometric coherence around Mt. Etna is highly variable. Some individual interferograms, however, are highly coherent for track-129 (Figure 3). The numbers of incoherent pixels for ascending and descending tracks are shown in Figure 4. Assuming that the deformation at relatively smooth in time, we apply a smoothing factor in forming the time series which helps remove residual atmospheric and orbital errors [13] (Figure 5). In our work, we use a smoothing factor 0.016 . Considering all interferograms, after excluding unreliable pixels in order to constrain the rate map between 2003 and 2007 for both tracks, we form two ratemaps for the ascending and descending tracks (Figure 6). The ratemaps suggest that subsidence occurred at rates exceeding $12 \mathrm{~mm} /$ year near the eastern flank of the summit for ascending track and for descending track. To the south-west of summit and on northern flank the ratemaps suggest that there is some inflation at rates of $10-12 \mathrm{~mm} /$ year. Individually, for each track, associated error maps are indicated that the corresponding error displacements are $0-3 \mathrm{~mm} / \mathrm{year}$ (Figure 7 and Figure 8).

\section{Separation of Time into Three Periods}

From the time-series analysis in Figure $\mathbf{5}$ and observed activity at Etna, the displacements are not linear with time (over the 4 years). The best fitting rate of displacement for these periods is far from the actual rate. To understand the behavior at Etna, we decided to divide the time interval into three sub-intervals: 2003-05; 2006; 2007. By examining the different rates during the three periods, we investigate the inflation and deflation activity during the time. Figure 9 shows the difference in position of two points located on the eastern and western flank of the volcano. Observation on track-129, within the first period (2003-05), suggests a maximum subsidence rate of 

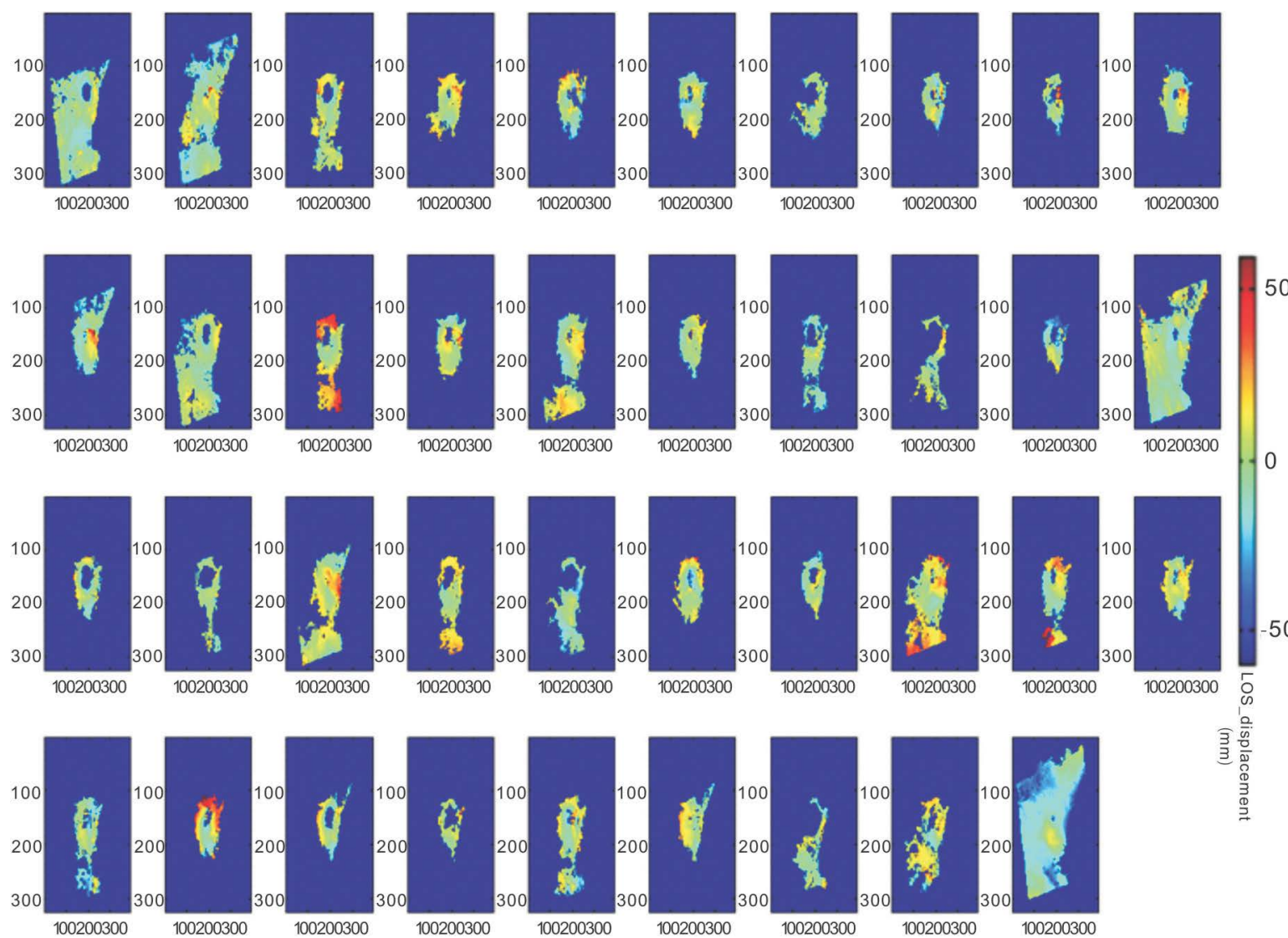

Figure 3. An example of all geocoded, unwrapped interferograms for ascending data.

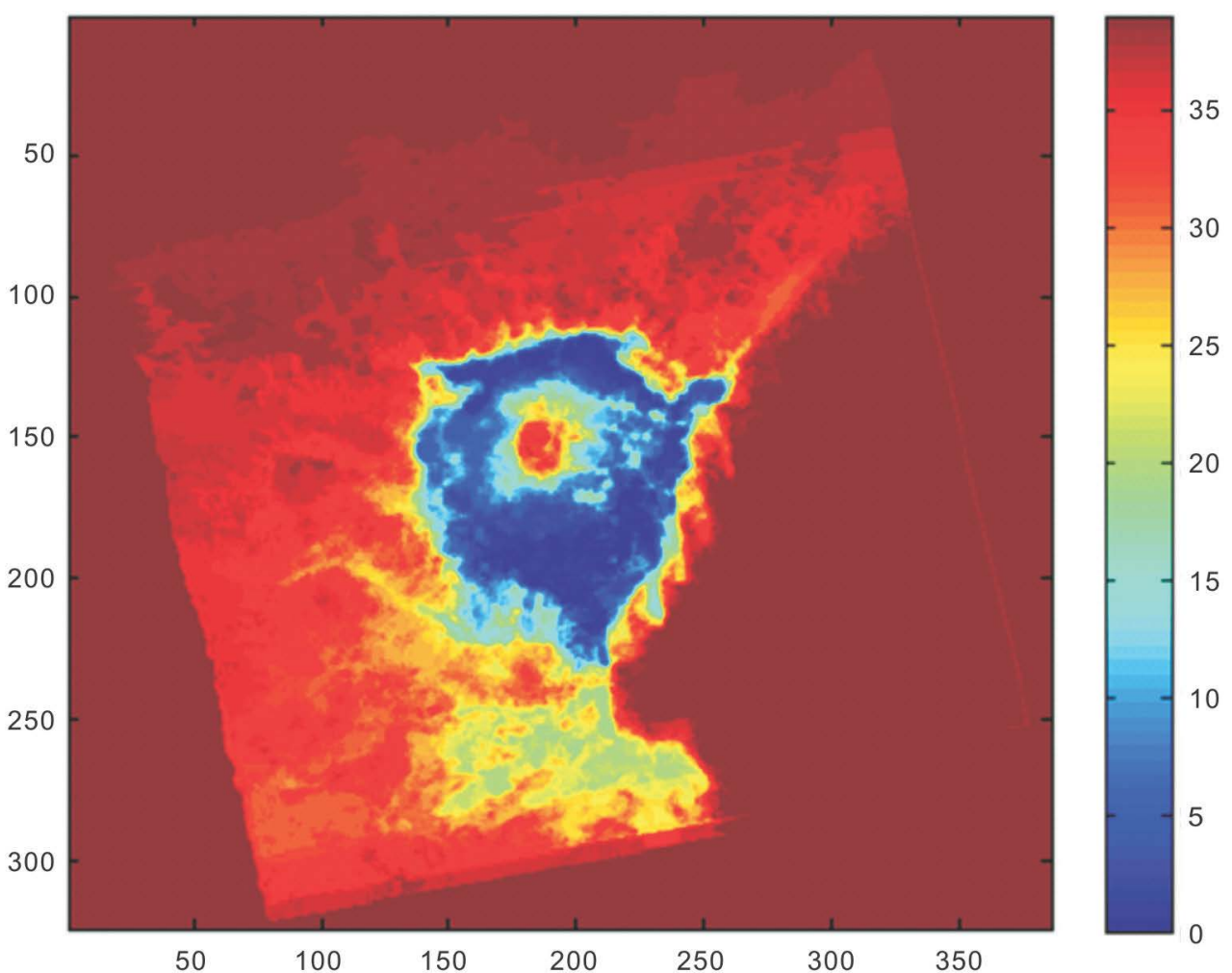




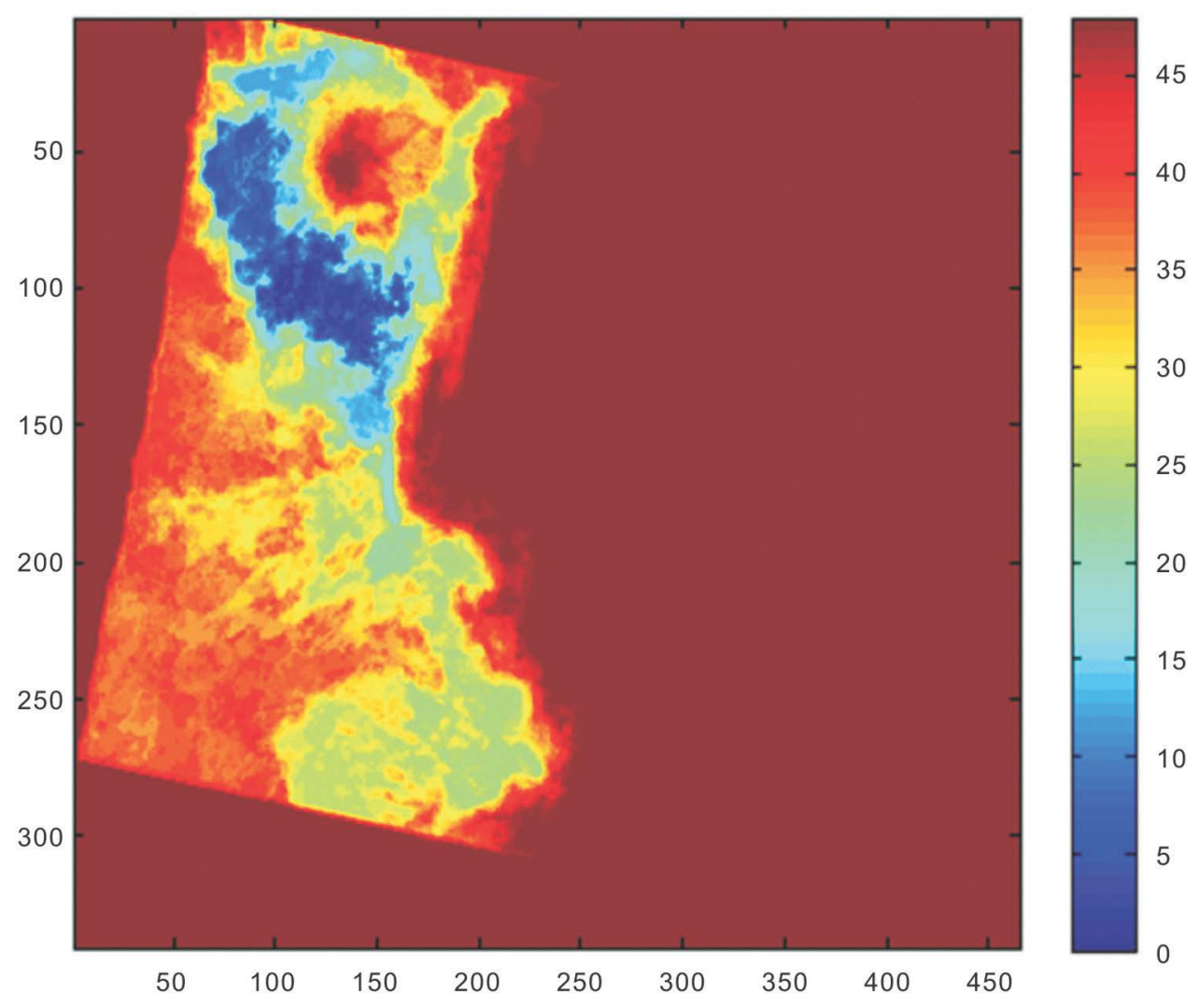

Figure 4. Number of incoherent pixel for ascending and descending tracks.

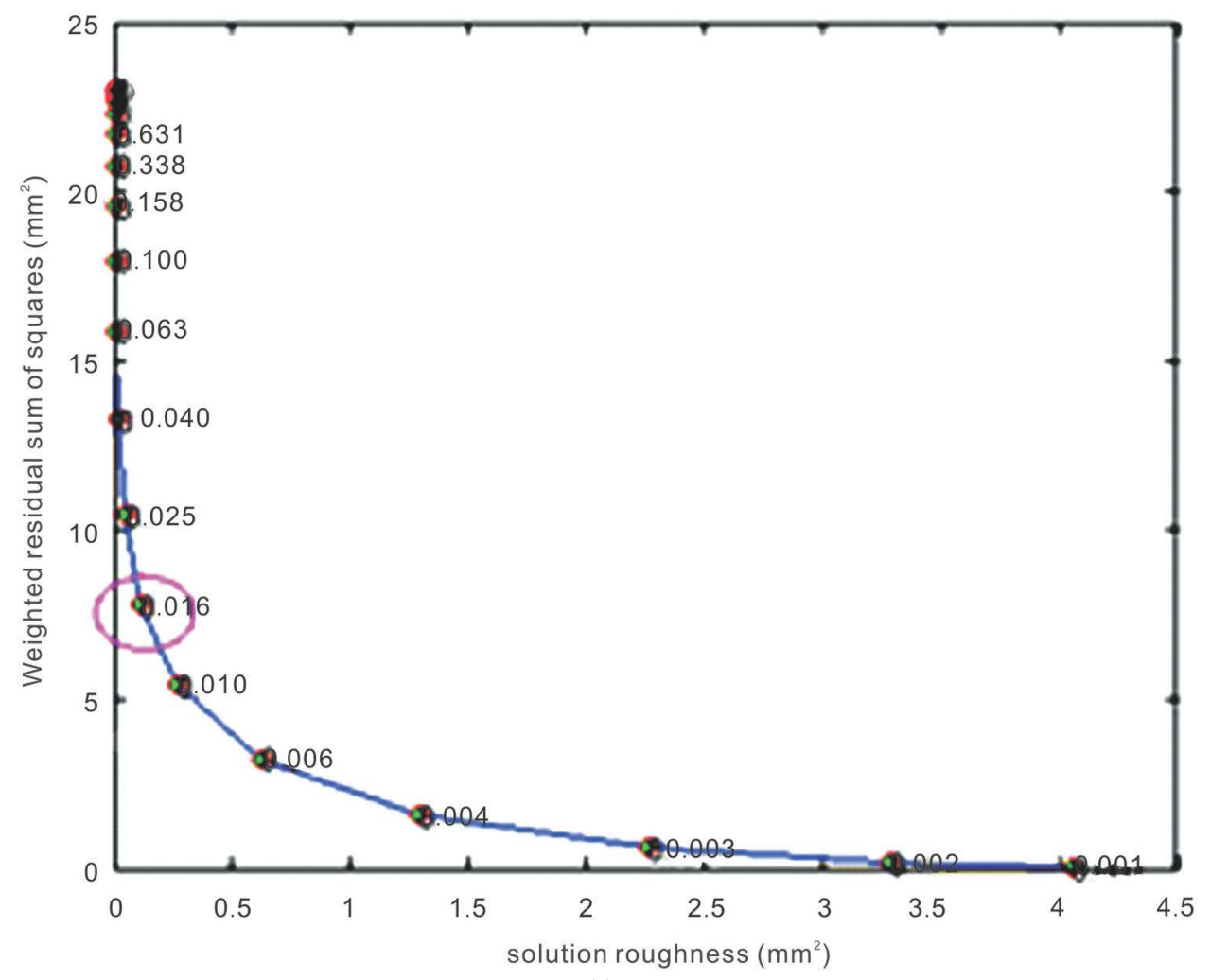

(a) 


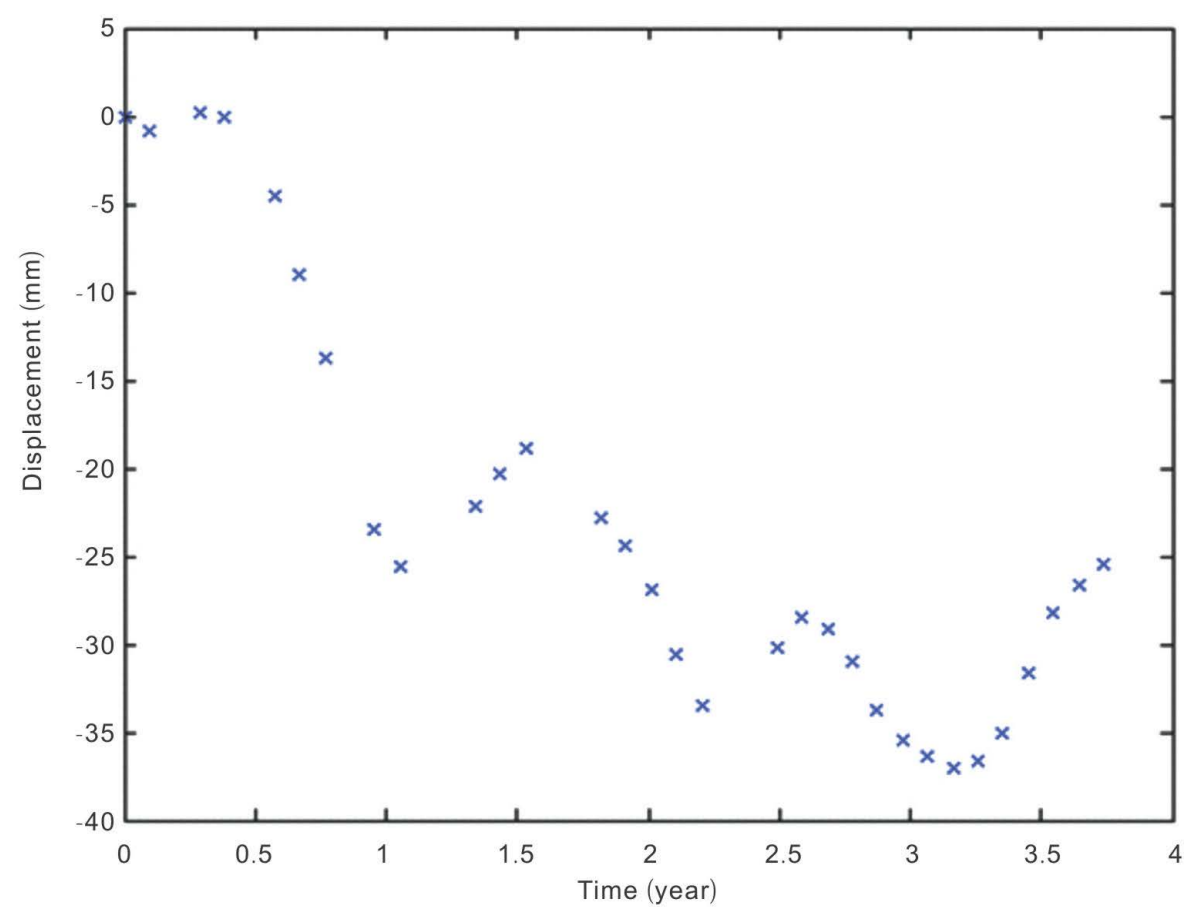

(b)

Figure 5. (a) Characterizes the tradeoff between solution roughness and weighted residual sum of squares; (b) Estimated time-series of cumulative displacement and time (year) for smoothing factor 0.016 at a fixed pixel respectively.

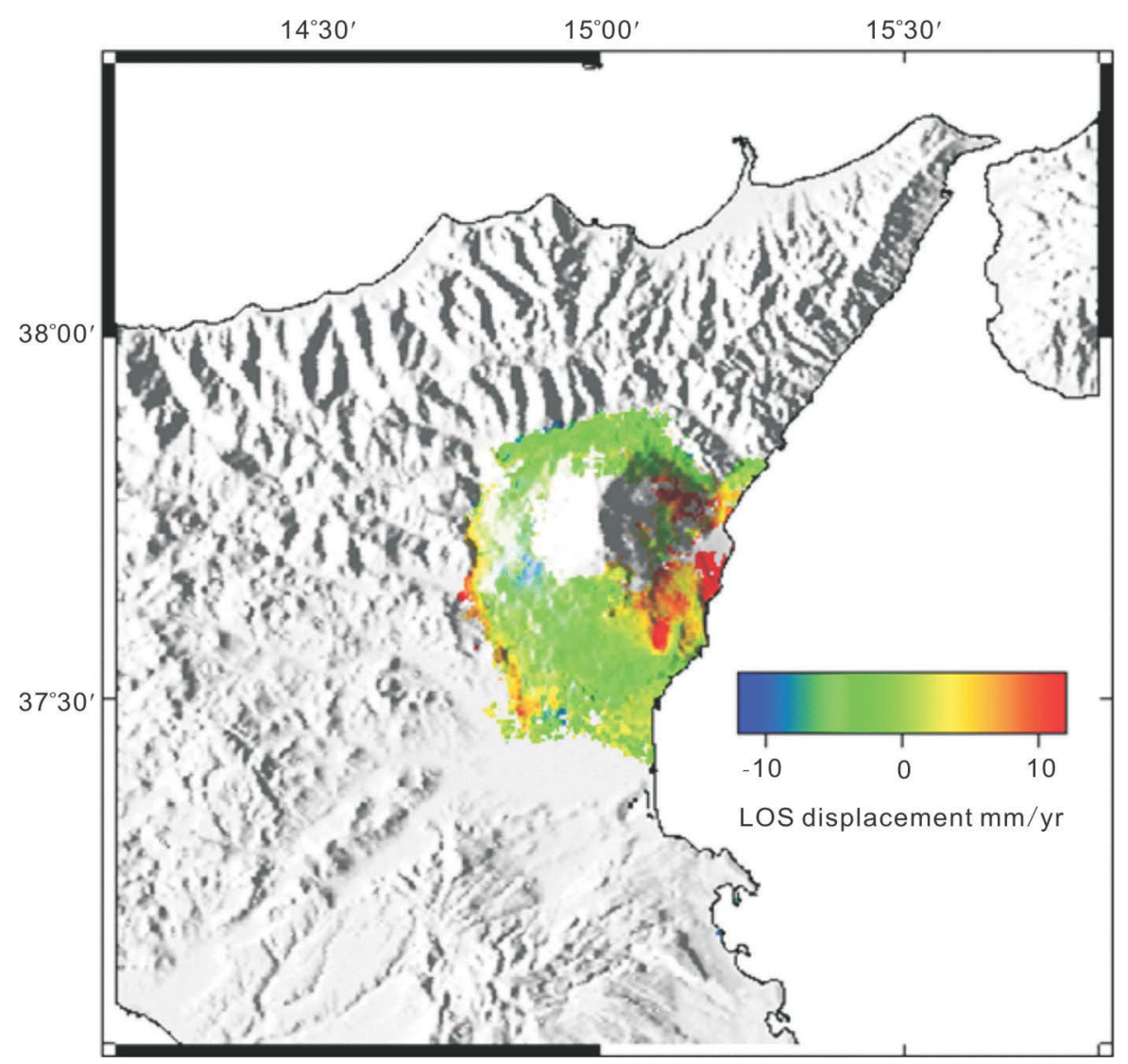




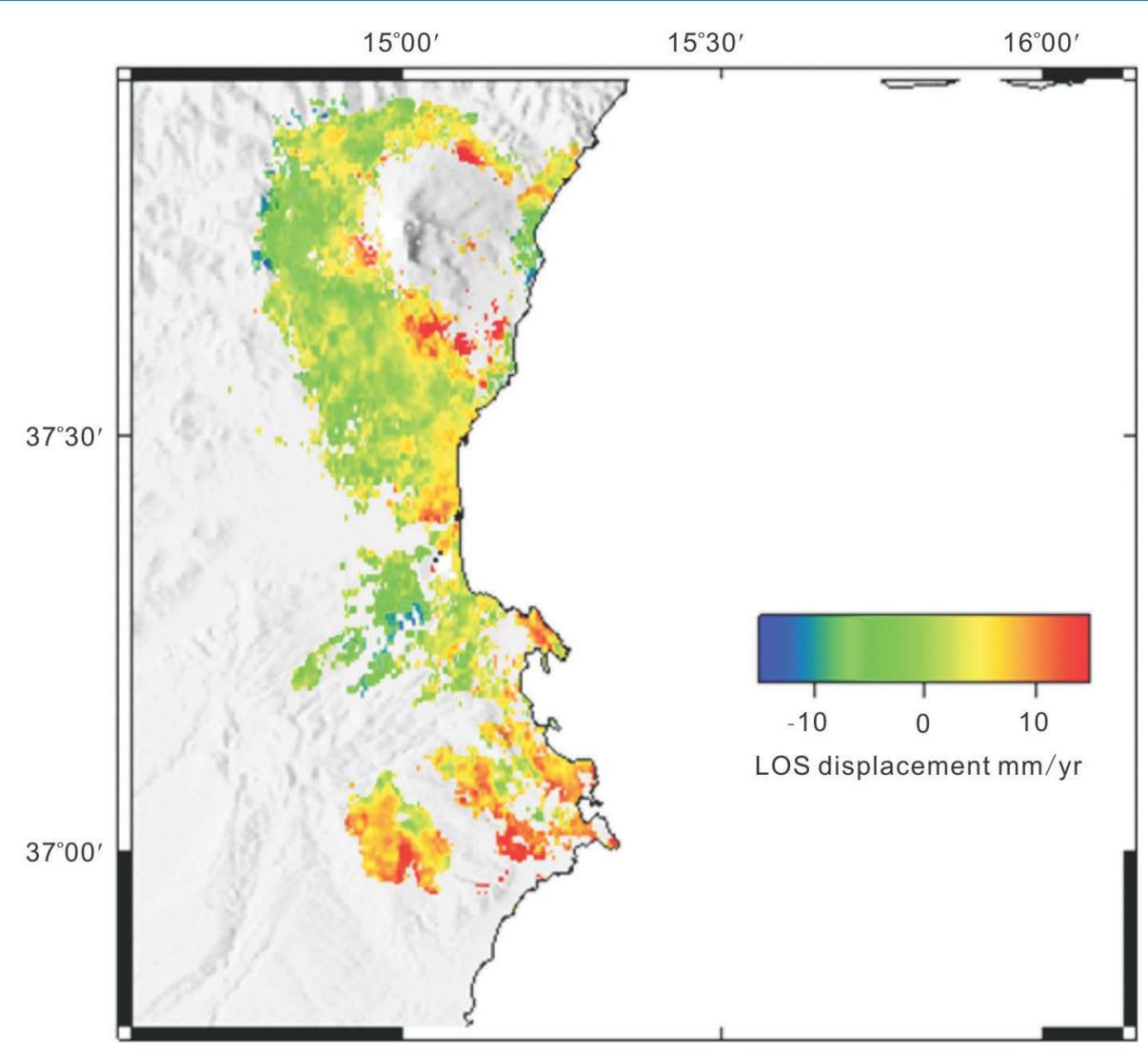

Figure 6. Rate map for both ascending and descending data respectively.

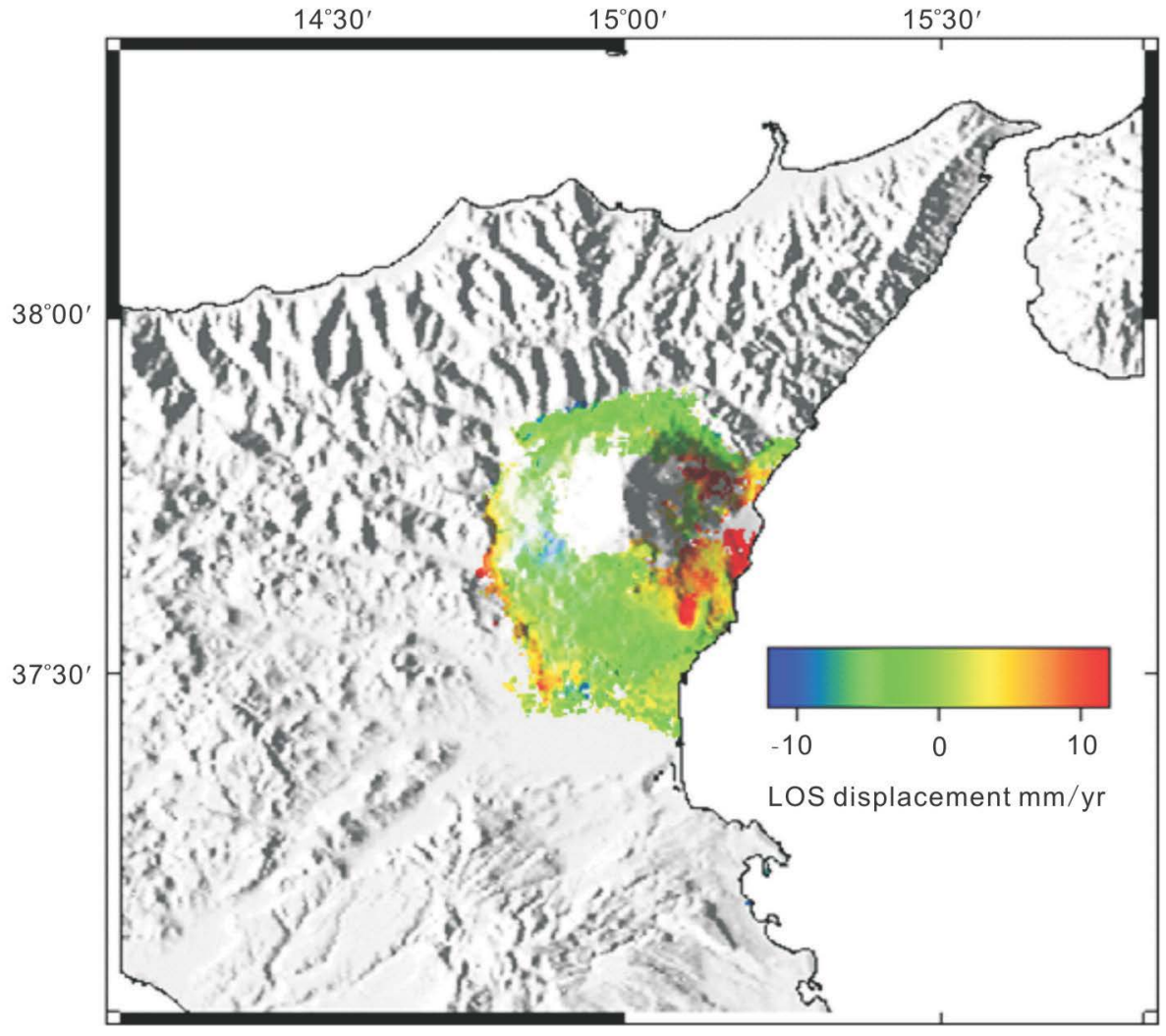




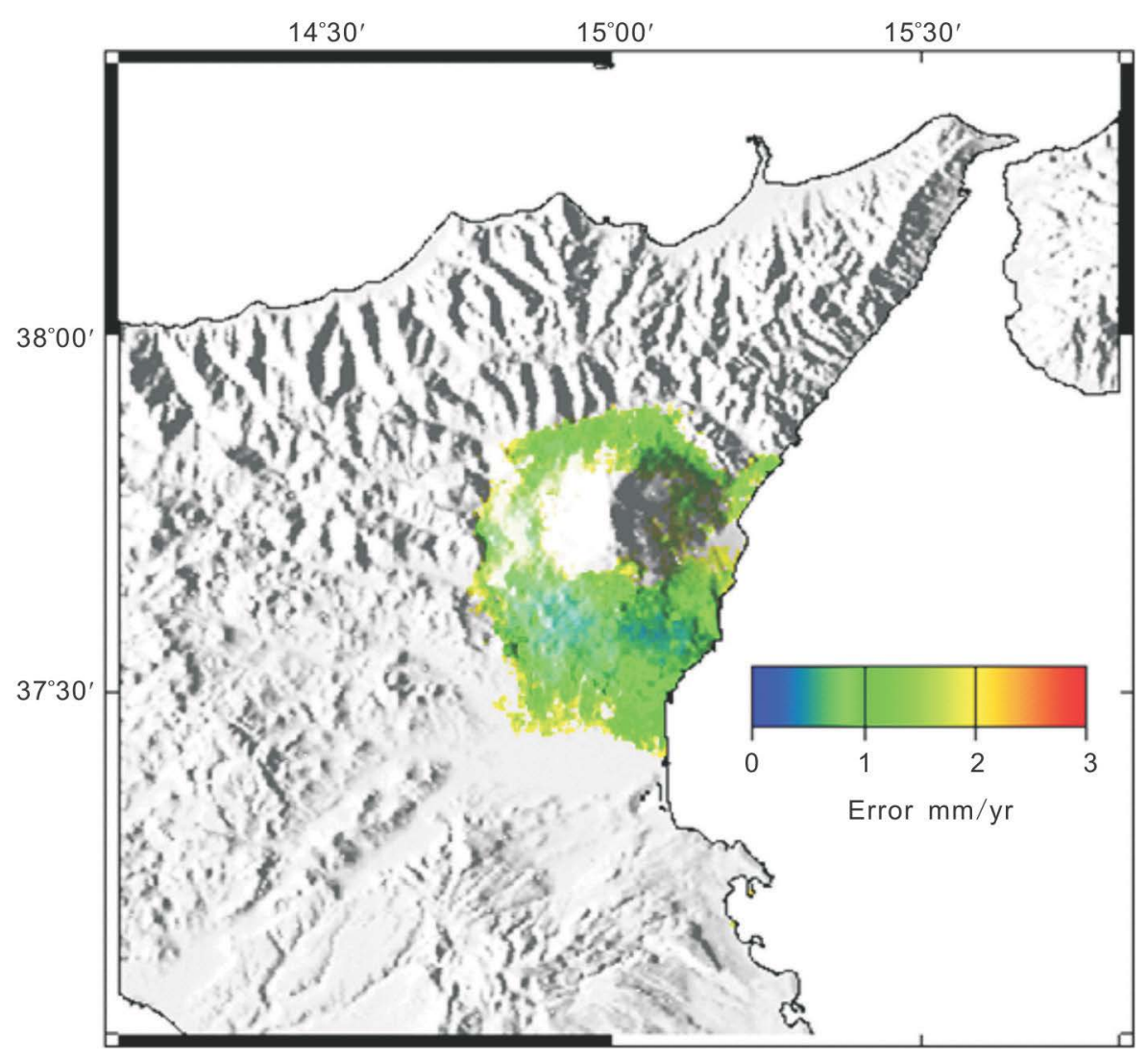

Figure 7. Ascending LOS Rate map and associated errors.

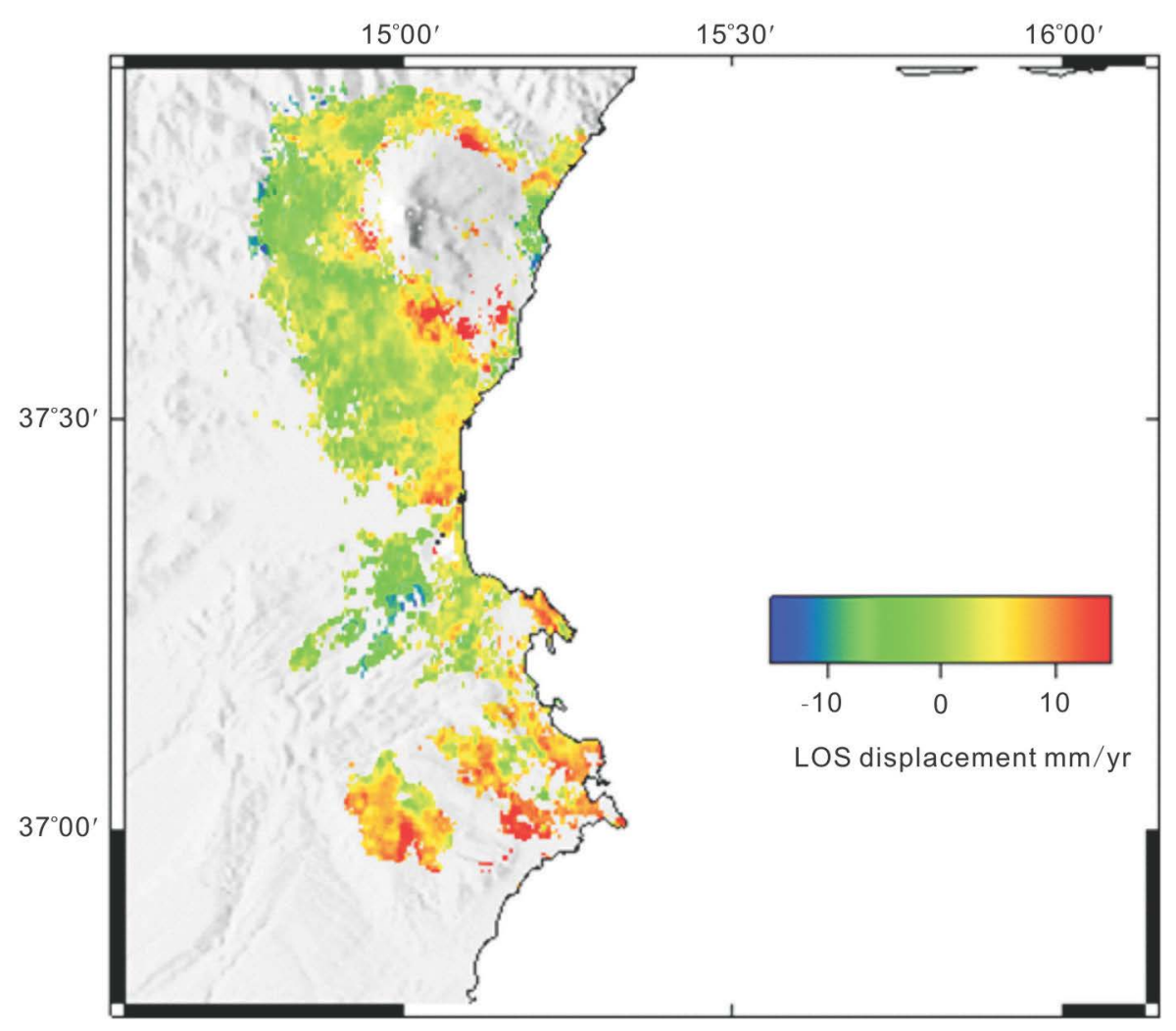




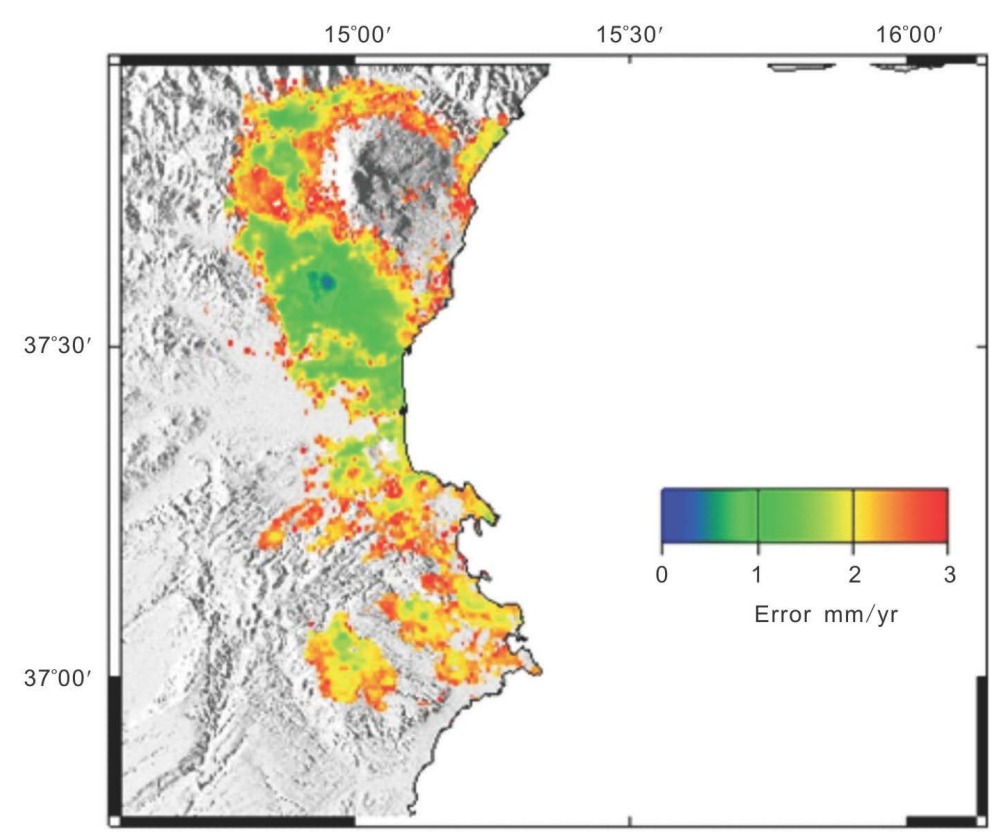

Figure 8. Descending LOS Rate map and associated errors.
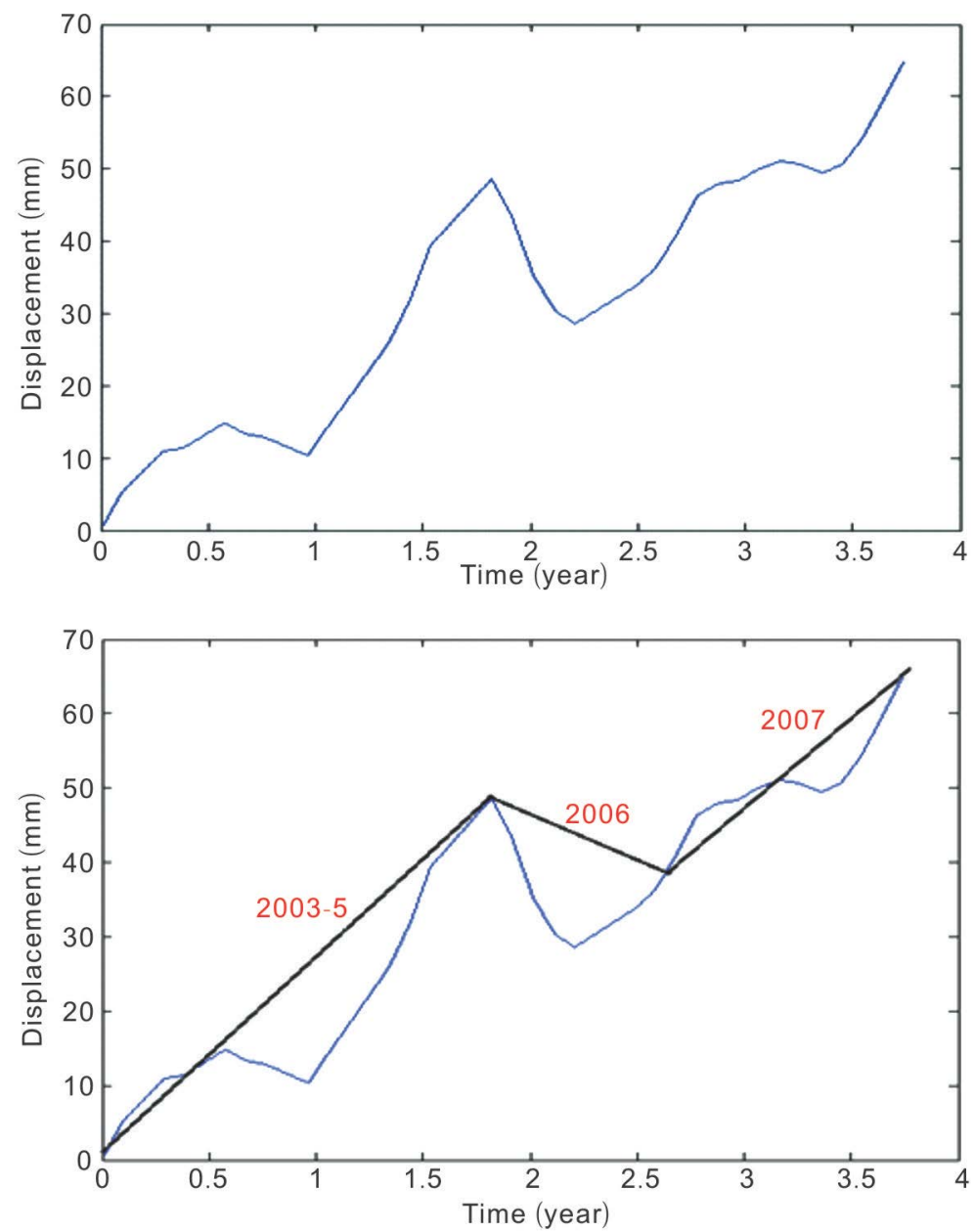

Figure 9. East-west cumulative displacement with time. 
$48 \mathrm{~mm} /$ year and during 2006, it reduced to approximately $35 \mathrm{~mm} /$ year. In 2007 this rate increases again to almost $65 \mathrm{~mm} /$ year. Figure 10 shows, between 2003 and 2005, that deflation affected mostly north-east flank close to the summit of Etna. The rate maps, during this period, suggest that the flow pattern of magma was not associated to the west flank. Conversely, during 2006, volcanic activity and displacement rates decreased but the inflation of volcanic edifice was still significant, as observed in the ratemaps for the period in both the ascending and descending data.
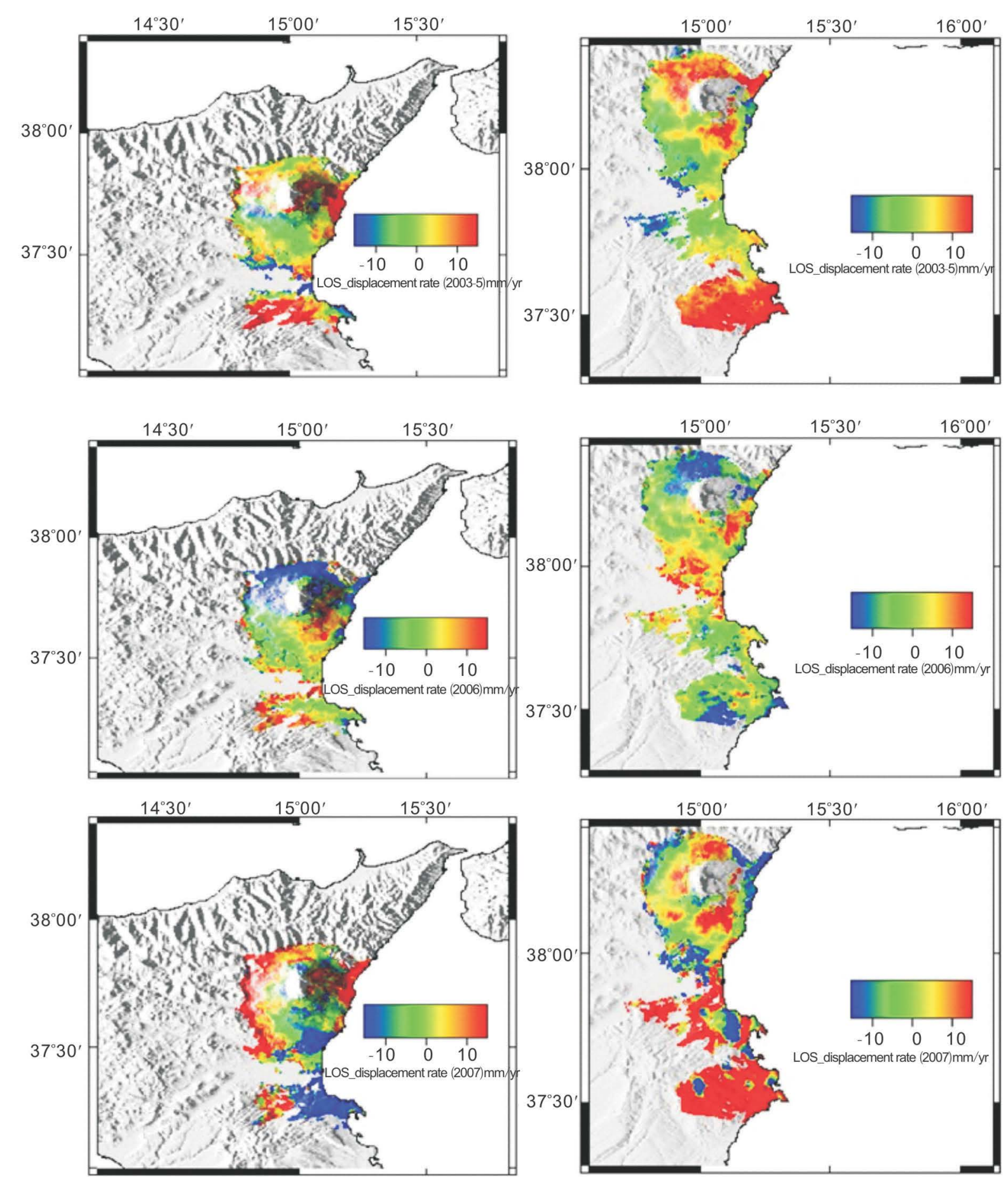

Figure 10. The image of the displacement rate map showing average displacement $\mathrm{mm} / \mathrm{yr}$ variations retrieved by applying InSAR technique during 2003-05, 2006 and 2007 respectively. Left: Ascending LOS; Right: Descending LOS. 
However, both in ascending and descending ratemaps during the 2007 period show that the deflation of the summit significantly increases. Only the north-east corner was not associated to magma flow.

\begin{tabular}{ccc}
\hline Time Duration (year) & Ascending Data Error (mm/year) & Descending Data Error (mm/year) \\
\hline $2003-05$ & \pm 1.4 & \pm 1.5 \\
2006 & \pm 4.8 & \pm 5.7 \\
2007 & \pm 6.73 & \pm 8.8 \\
\hline
\end{tabular}

Examining the errors associated with each of the three periods shows that the first period for the both tracks are much less than the later two. This is because; there is more data for the first two years compared to other two periods of one year. Observations from this work suggest that, during 2006 the emission of magma from summit craters or from fractures close to the main craters appears to switch from a period of deflation to a period of inflation.

\section{Conclusion}

The main importance of this work is to investigate the changes in the surface displacement at Mt. Etna, related to the inflation/deflation of volcanic edifice. The result obtained by this work indicates different rates of magma accumulation and withdrawal during the observation period. The time-series inversion shows three sub-intervals of time. It also shows that InSAR is a powerful tool for investigating magma migration around Etna. Although we cannot comment on the long term behavior of the volcano, the results of this work indicate that the volcano also behaves on a yearly or 2 yearly scale. To further this study with an addition, it can be possible to use simple analytic and numerical models to quantify the volume of materials coming in and out of volcanoes. Furthermore, it will be possible to combine ascending-descending data to solve for vertical and E-W displacements.

\section{References}

[1] Patanè, D., Aliotta, M., Cannata, A., Cassisi, C., Coltelli, M., Di Grazia, G., Mon-talto, P., Zuccarello, L., et al. (2011) Interplay between Tectonics and Mount Etna's Volcanism: Insights into the Geometry of the Plumbing System. New Frontiers in Tectonic Research - At the Midst of Plate Convergence, 73-77.

[2] Jacquelyne Kious, W. and Tilling, R.I. (1996) This Dynamic Earth: The Story of Plate Tectonics. Diane Publishing, USA.

[3] Neri, M., Casu, F., Acocella, V., Solaro, G., pepe, S., Berardino, P., Sansosti, E., Caltabiano, T., Lundgren, P. and Lanari, R. (2009) Deformation and Eruptions at Mt. Etna (Italy): A Lesson from 15 Years of Observations. Geophysical Research Letters, 36, 1.

[4] Turner, J.S. and Campbell, I.H. (1986) Convection and Mixing in Magma Chambers. Earth Science Reviews, 23, 255352. http://dx.doi.org/10.1016/0012-8252(86)90015-2

[5] Gudmundsson, A. (2006) How Local Stresses Control Magma-Chamber Ruptures, Dyke Injections, and Eruptions in Composite Volcanoes. Earth-Science Reviews, 79, 1-31. http://dx.doi.org/10.1016/j.earscirev.2006.06.006

[6] Wang, X., Boselli, A., D’Avino, L., Pisani, G., Spinelli, N., Amodeo, A., Chaikovsky, A., Wiegner, M., Nickovic, S., Papayannis, A., et al. (2008) Volcanic Dust Characterization by Earlinet during Etna's Eruptions in 2001-2002. Atmospheric Environment, 42, 893-905. http://dx.doi.org/10.1016/j.atmosenv.2007.10.020

[7] Neri, M., Giammanco, S., et al. (2010) Continuous Monitoring of Soil Radon Activity and Soil Temperature near the summit of Mt. Etna (Sicily, Italy) during 2007-2009: Correlations with Stress Field and Volcanic Activity. Cities on Volcanoes 6 Conference.

[8] Neri, M., Acocella, V., Behncke, B., Giammanco, S., Mazzarini, F. and Rust, D. (2011) Structural Analysis of the Eruptive Fissures at Mount Etna (Italy). Annals of Geophysics, 54, 5.

[9] Doglioni, C., Innocenti, F. and Mariotti, G. (2001) Why Mt. Etna? Terra Nova, 13, 25-31. http://dx.doi.org/10.1046/j.1365-3121.2001.00301.x

[10] Behncke, B. and Neri, M. (2003) Cycles and Trends in the Recent Eruptive Behaviour of Mount Etna (Italy). Canadian Journal of Earth Sciences, 40, 1405-1411. http://dx.doi.org/10.1139/e03-052

[11] Branca, S. and Del Carlo, P. (2004) Eruptions of Mt. Etna during the Past 3200 Years: A Revised Compilation Inte grating the Historical and Stratigraphic Records. Geophysical Monograph-American Geophysical Union, 143, 1-28. 
[12] Patanè, D., Privitera, E., Gresta, S., Alparone, S., Akinci, A., Barberi, G., Chiaraluce, L., Cocina, O., D’Amico, S., De Gori, P., et al. (2003) Seismological Constraints for the Dyke Emplacement of the July-August 2001 Lateral Eruption at Mt. Etna Volcano, Italy. Annals of Geophysics, 46.

[13] Garthwaite, M.C. (2011) Deformation of Tibet: InSAR Analysis and Viscous Flow Models. Ph.D. Thesis, University of Leeds, Leeds.

[14] Al, F., Monti-Guarniery, A., Prari, C., Rocca, F. and Massonnet, D. (2007) InSAR Principles: Guidelines for Interferometry Processing and Interpretation: A Practical Approach, Parts a, b, c. ESA Publications, Noordwijk.

[15] Wright, T.J., Parsons, B., England, P.C. and Fielding, E.J. (2004) InSAR Observations of Low Slip Rates on the Major Faults of Western Tibet. Science, 305, 236-239. http://dx.doi.org/10.1126/science.1096388

[16] Wang, H., Biggs, J. and Wright, T.J. (2010) $\pi$-Rate (v2. 0b2) Poly-Interferogram Rate and Time-Series Estimator. University of Leeds, Leeds. 
Scientific Research Publishing (SCIRP) is one of the largest Open Access journal publishers. It is currently publishing more than 200 open access, online, peer-reviewed journals covering a wide range of academic disciplines. SCIRP serves the worldwide academic communities and contributes to the progress and application of science with its publication.

Other selected journals from SCIRP are listed as below. Submit your manuscript to us via either submit@scirp.org or Online Submission Portal.
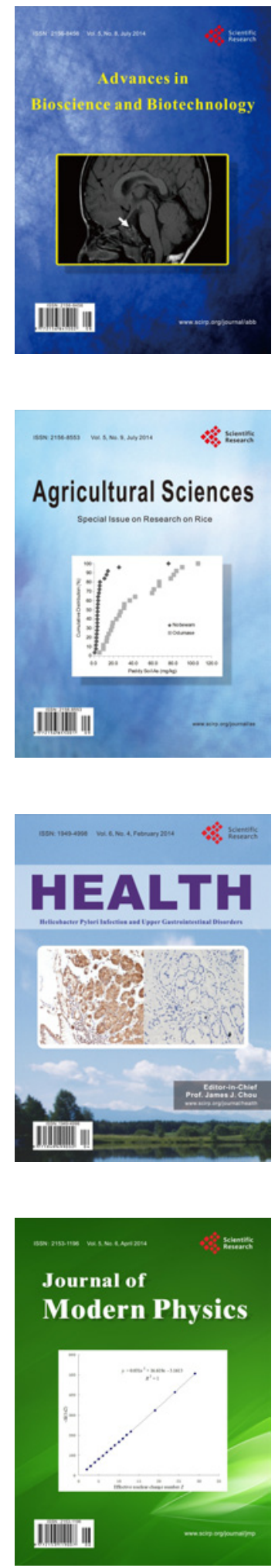
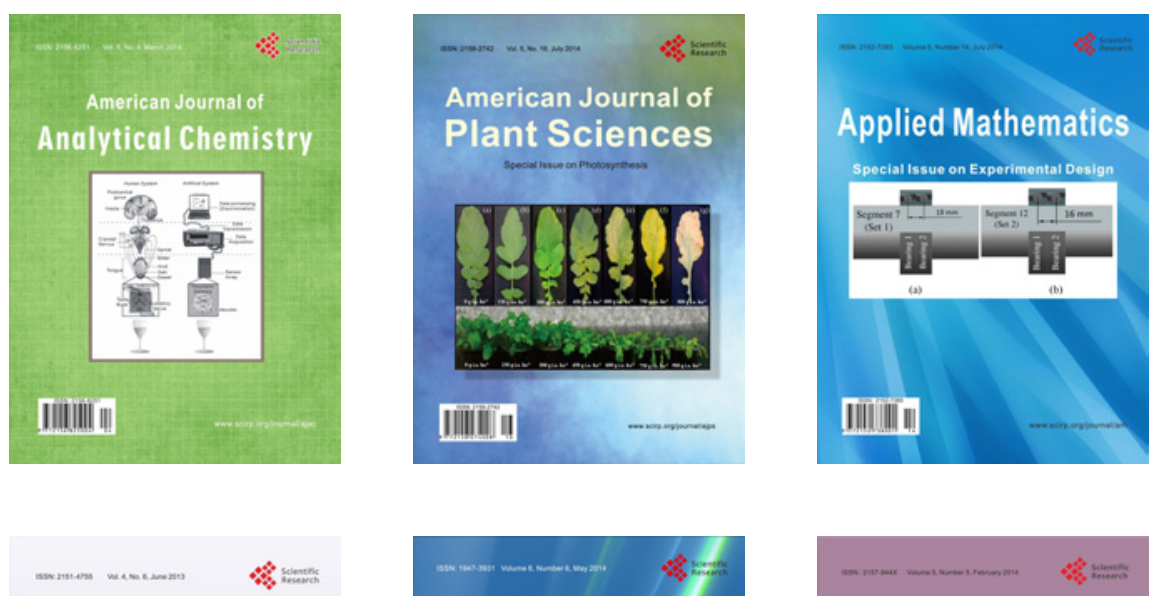

Creative Education
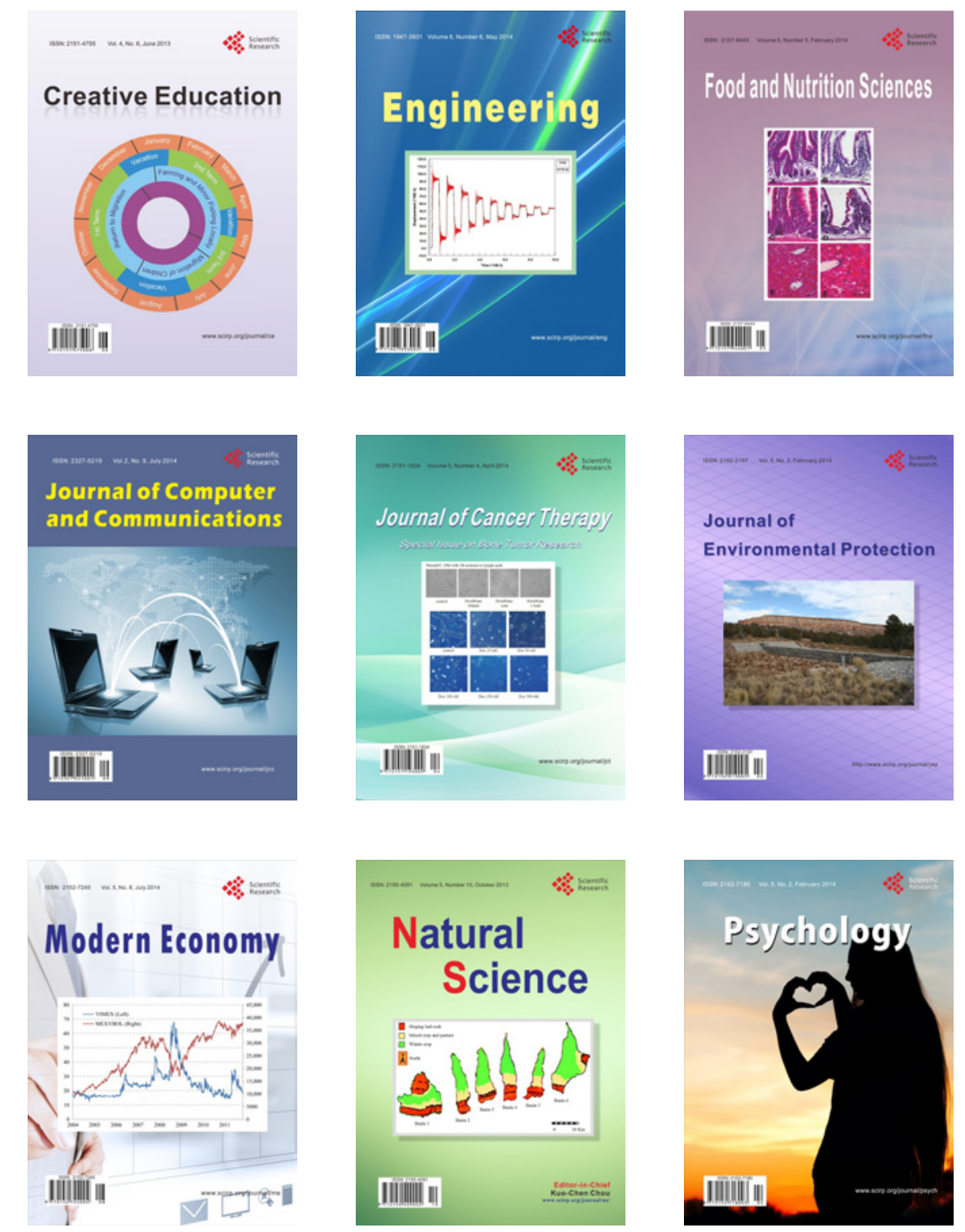